\title{
The rise and fall of the craniocervical junction relative to the hard palate: a lifetime story
}

\author{
Grant W. Mallory, MD, ${ }^{1}$ Grigoriy Arutyunyan, MD, ${ }^{2}$ Meghan E. Murphy, MD, ${ }^{1}$ \\ Kathryn M. Van Abel, MD, ${ }^{3}$ Elvis Francois, MD, ${ }^{2}$ Nicholas M. Wetjen, MD, ${ }^{1}$ \\ Jeremy L. Fogelson, MD, ${ }^{1}$ Erin K. O'Brien, MD, ${ }^{3}$ Michelle J. Clarke, MD, \\ Laurence J. Eckel, MD, ${ }^{4}$ and Jamie J. Van Gompel, MD ${ }^{1,3}$ \\ Departments of ${ }^{1}$ Neurological Surgery, ${ }^{2}$ Orthopedics, ${ }^{3}$ Otolaryngology, and ${ }^{4}$ Radiology, Mayo Clinic, Rochester, Minnesota
}

\begin{abstract}
OBJECT Endoscopic approaches to the anterior craniocervical junction are increasing in frequency. Choice of oral versus endoscopic endonasal approach to the odontoid often depends on the relationship of the C1-2 complex to the hard palate. However, it is not known how this relevant anatomy changes with age. We hypothesize that there is a dynamic relationship of C-2 and the hard palate, which changes with age, and potentially affects the choice of surgical approach. The aim of this study was to characterize the relationship of C-2 relative to the hard palate with respect to age and sex.

METHODS Emergency department billing and trauma records from 2008 to 2014 were reviewed for patients of all ages who underwent cervical or maxillofacial CT as part of a trauma evaluation for closed head injury. Patients who had a CT scan that allowed adequate visualization of the hard palate, opisthion, and upper cervical spine (C-1 and C-2) were included. Patients who had cervical or displaced facial/skull base fractures, a history of rheumatoid arthritis, or craniofacial anomalies were excluded. The distance from McGregor's palatooccipital line to the midpoint of the inferior endplate of C-2 (McL-C2) was measured on midsagittal CT scans. Patients were grouped by decile of age and by sex. A 1-way ANOVA was performed with each respective grouping.
\end{abstract}

RESULTS Ultimately, 483 patients ( $29 \%$ female) were included. The mean age was $46 \pm 24$ years. The majority of patients studied were in the 2 nd through 8 th decades of life (85\%). Significant variation was found between McL-C2 and decile of age $(p<0.001)$ and sex $(p<0.001)$. The mean McL-C2 was $27 \mathrm{~mm}$ in the 1 st decade of life compared with the population mean of $37 \mathrm{~mm}$. The mean McL-C2 was also noted to be smaller in females (mean difference $4.8 \mathrm{~mm}, p<$ $0.0001)$. Both decile of age $(p=0.0009)$ and $\operatorname{sex}(p<0.0001)$ were independently correlated with McL-C2 on multivariate analysis.

CONCLUSIONS The relationship of C-2 and the hard palate significantly varies with respect to age and sex, descending relative to the hard palate a full centimeter on average in adulthood. These findings may have relevance in determining optimal surgical approaches for addressing pathology involving the anterior craniocervical junction.

http://thejns.org/doi/abs/10.3171/2015.6.SPINE141250

KEY WORDS cervicomedullary junction; craniocervical; C-1; C-2; anatomy; endoscopic approaches; cervical

$\mathrm{T}$ HE conventional approach to pathology of the ventral craniocervical junction remains the transoral route with or without various modifications to increase exposure as required by pathology. ${ }^{20}$ However, combining the transoral route with splitting of the soft palate, maxillotomy, glossotomy, or mandibulotomy also increases morbidity. ${ }^{6,22,28}$ To avoid additional tissue disruption, retraction of the soft palate and other approaches have been considered with or without the adjunct of an endoscope to improve exposure. ${ }^{24}$ Other alternatives include a high anterolateral approach, endoscopic transoral (EO), transnasal (EN), or transcervical approaches. . $^{12,14,15,30}$ While each of these approaches varies in the angle of attack and respective surgical corridors, the various approaches are individualized to patient anatomy and pathology with the goal of causing less tissue disruption and maximization of natural corridors. One major anatomical constraint that determines the sagittal exposure of the transoral and transnasal routes, whether endoscopic or under the microscope, is the hard palate (Fig. 1). Radiographic lines such as the

ABBREVIATIONS EN = endoscopic transnasal; EO = endoscopic transoral; McL-C2 = distance from McGregor's palatooccipital line to the midpoint of the inferior endplate of C-2.

SUBMITTED December 13, 2014. ACCEPTED June 18, 2015.

INCLUDE WHEN CITING Published online December 11, 2015; DOI: 10.3171/2015.6.SPINE141250. 


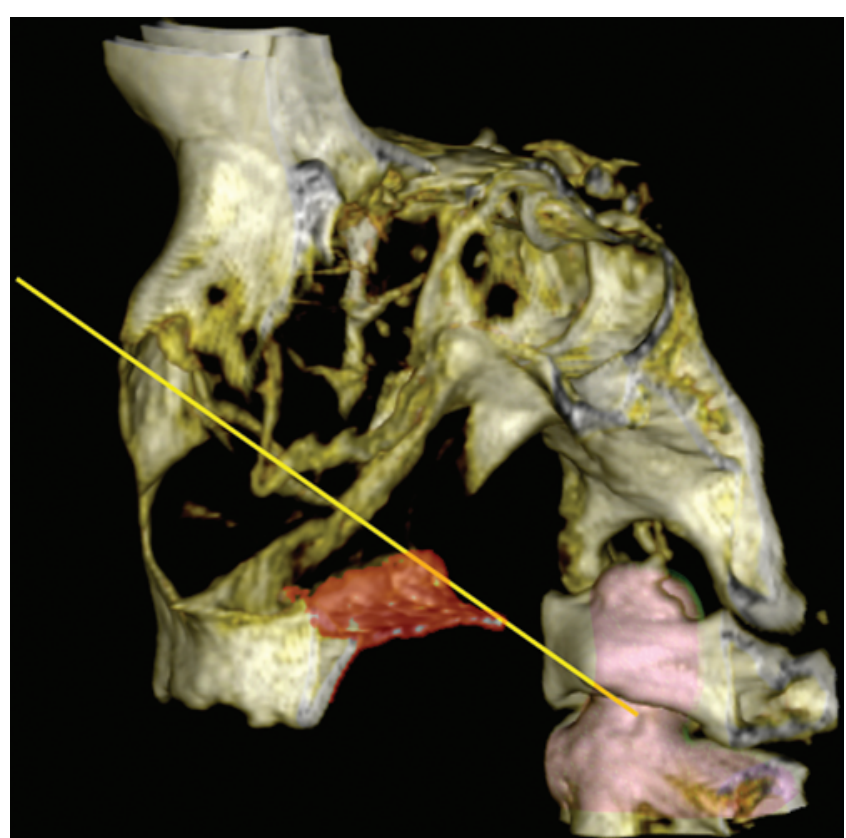

FIG. 1. A 3D CT reconstruction showing the anatomical constraints of the endonasal corridor. The steepest inferior trajectory (yellow line) for pathology of the axis (pink) is limited by the hard palate (red). Figure is available in color online only.

nasopalatine, and more recently, rhinopalatine have been proposed for predicting the inferior extent of the EN corridor, whereas the oropalatine line has been proposed for predicting the cephalad extent of exposure of the transoral route. $8,17,18$

Although each respective corridor has been partially evaluated in cadaveric and radiographic studies of small case series, ${ }^{2,8,18,23,29,31}$ the extent to which age causes these corridors to vary has not been adequately addressed. Banu and colleagues found both the working angle and distance of the EN corridor differed with age in a pediatric population. ${ }^{4}$ As the $\mathrm{C} 1-2$ and hard palate relationship predicts the sagittal extent of exposure with EN approaches, we hypothesize that the relationship changes with age, similar to the working angle as described by Banu et al. While this relationship likely also changes with respect to sex, as suggested by radiographic studies evaluating normal variance of markers for basilar invagination, ${ }^{16,25}$ we also assessed and controlled for sex variation. The present study sought to characterize the anatomical relationship of C-2 and the hard palate with age and sex using sagittal CT.

\section{Methods \\ Selection Criteria}

Following approval by our institutional review board, emergency department billing and trauma records from 2008 to 2014 were searched for patients undergoing evaluation of closed head injuries who concomitantly underwent cervical CT and/or maxillofacial CT as part of their trauma workup. Those patients who had cervical or displaced facial/skull base fractures, a history of rheumatoid arthritis, or craniofacial anomalies were excluded. Addi-

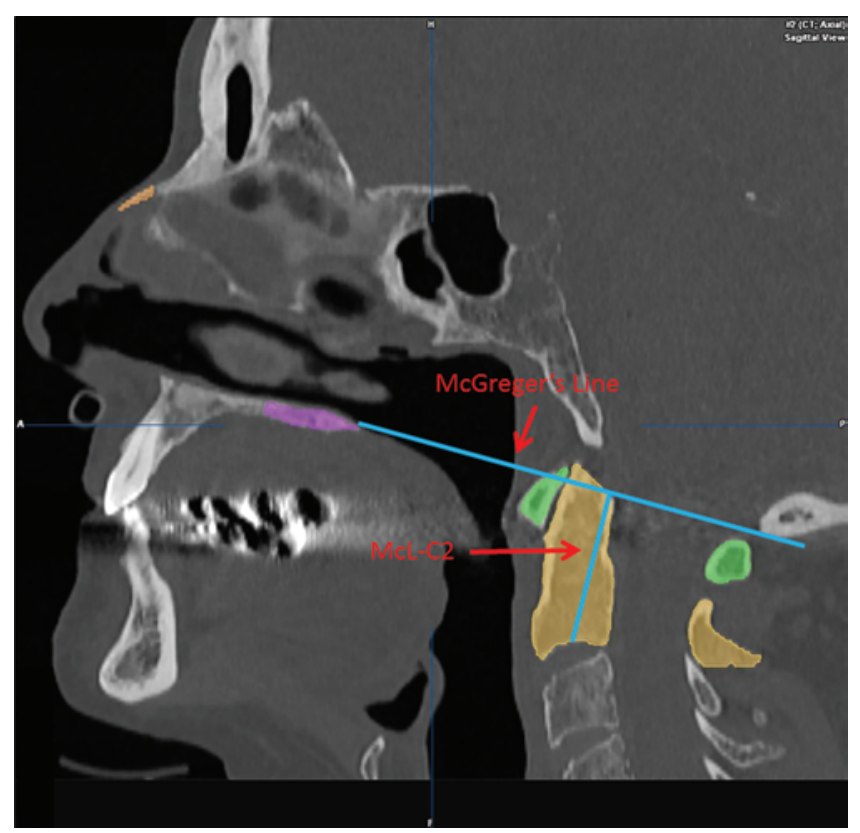

FIG. 2. Midsagittal CT scan illustrating the distances measured to assess the relationship of $\mathrm{C}-2$ (yellow) to the hard palate (pink). The relationship to $\mathrm{C}-1$ (green) and the nasal bone (orange) is also shown. McGregor's palatooccipital line is used as a reference, and a perpendicular line is drawn to the midpoint of inferior C-2 endplate (McL-C2) as described by Redlund-Johnell. ${ }^{22,26}$ Figure is available in color online only.

tional exclusions were made if the available CT scans did not allow adequate visualization of the hard palate, opisthion, the $\mathrm{C}-1 \mathrm{ring}$, or the inferior endplate of $\mathrm{C}-2$. Age, sex, and racial data were gathered for all patients meeting the inclusion criteria.

\section{Radiographic Measurements}

Methods previously described by McGregor $^{22}$ and Redlund-Johnell ${ }^{26}$ to assess cranial settling on plain radiographs were chosen to assess the normal variance of the relationship between $\mathrm{C}-2$ and the hard palate and skull base. Both methods have established inter- and intrarater reliability. ${ }^{16}$ Additionally, they provide a reference line in the sagittal plane that can be used on both CT modalities if presented with the inability to visualize the nasal cavity in all studies. All measurements were performed on midsagittal CT slices. A perpendicular distance was measured from a reference line extending from the tip of the hard palate to the base of the opisthion (McGregor's palatooccipital line) to the midpoint of the inferior C-2 endplate (McL-C2) or from a modified Redlund-Johnell's line in millimeters. An example of the criterion is shown in Fig. 2.

\section{Statistical Analysis}

All statistical analysis was performed with JMP 10 software (SAS Institute Inc.) in consultation with a biostatistician. Patients were first grouped by decile of age and sex. Further stratification was also performed in the pediatric age group by every 4 years of age, starting from ages 2 to 5 years and including patients up to 18 years of 
age. A 1-way ANOVA was used to assess the variability of $\mathrm{McL}-\mathrm{C} 2$ based on decile of age, sex, and every 4 years of age (pediatric patients only). Multivariate regression was also performed to assess whether decile of age and sex were independently associated with $\mathrm{McL}-\mathrm{C} 2$.

\section{Results}

After applying exclusion criteria to potential study candidates identified with the initial search methods $(\mathrm{n}=$ 684 ), 483 patients were included. The mean age of the cohort was $45.9 \pm 24$ years (range $2-94$ years). Sixteen percent $(n=77)$ of the patients were less than 18 years of age. Males comprised the majority of the patient population (70\%). The racial demographic was predominantly Caucasian (89\%), followed by Hispanic (5.2\%) and AfricanAmerican (3.1\%). Asians and Native Americans made up $0.8 \%$, whereas $2.3 \%$ were either biracial or preferred not to have their racial demographic displayed in their electronic medical record. The mean McL-C2 varied significantly according to sex, as shown in Table 1 . McL-C2 was noted to be shorter in females, with the mean difference being $4.8 \mathrm{~mm}(\mathrm{p}<0.0001)$.

Patients were further stratified by decile of age. The majority of patients studied were in the 2nd through 8th decades of life (85\%). The smallest represented decile was the 10th decade (90-99 years of age), which comprised 15 patients (3\%). ANOVA demonstrated significant variance ( $\mathrm{p}<0.0001)$ of McL-C2 according to age decile (Fig. 3). $\mathrm{McL}-\mathrm{C} 2$ was shortest at the extremes of age. The mean $\mathrm{McL}-\mathrm{C} 2$ was $27.0 \mathrm{~mm}$ in the 1st decade of life compared with the population mean of $36.5 \mathrm{~mm}( \pm 4.8 \mathrm{~mm})$. Similarly, the mean McL-C2 was $33.6 \mathrm{~mm}$ in patients in their 10 th decade of life. The maximum mean McL-C2 value was noted in the 4th decade of life $(38.6 \mathrm{~mm})$.

Grouping was also performed in the pediatric subset (individuals 18 years or less) by every 4 years starting from 2 to 5 years of age. The least represented group were patients aged from 6 to 9 years $(n=6[7.8 \%])$ and 10 to 13 years $(n=8[10.3 \%])$. One-way ANOVA also demonstrated significant variance in the mean $\mathrm{McL}-\mathrm{C} 2$ within this subset ( $p<0.0001$ ), as shown in Fig. 4. The overall population mean of $\mathrm{McL}-\mathrm{C} 2$ was $34.0 \pm 6.0 \mathrm{~mm}$. A continued increase was noted in the mean McL-C2 from children aged 2 to 5 years $(25.1 \mathrm{~mm})$ to individuals that were 18 years of age $(37.3 \mathrm{~mm})$. The most significant increase was noted between age subsets 2-5 years and 6-9 years, with the mean difference in McL-C2 being $6 \mathrm{~mm}$.

As both decile of age and sex were found to be significantly associated with $\mathrm{McL}-\mathrm{C} 2$, multivariate regression was performed to assess independence. Both decile of age $(\mathrm{p}<0.001)$ and sex $(\mathrm{p}<0.0001)$ were independently predictive of $\mathrm{McL}-\mathrm{C} 2$.

\section{Discussion}

In the present study, we selectively tracked the relationship between C-2 and the hard palate and found significant variation with age and sex. Specifically, we found that the distance from the base of C-2 to the hard palate (determined by $\mathrm{McL}-\mathrm{C} 2$ measurement) is significantly shorter at the extremes of age and in females compared
TABLE 1. Mean distances of $\mathrm{C}-2$ relative to the hard palate according to sex and age*

\begin{tabular}{|c|c|c|}
\hline Variable & McL-C2 & $p$ Value \\
\hline Sex & & $<0.0001$ \\
\hline $\mathrm{F}$ & $33.1(4.5) \dagger$ & \\
\hline $\mathrm{M}$ & $37.9(4.2) \dagger$ & \\
\hline Decade, age decile & & $<0.0001$ \\
\hline 1st, $0-9$ yrs & $27.0(0.94)$ & \\
\hline 2nd,10-19 yrs & $36.4(0.53)$ & \\
\hline $3 r d, 20-29$ yrs & $37.3(0.47)$ & \\
\hline 4th, $30-39$ yrs & $38.6(0.61)$ & \\
\hline 5th, $40-49$ yrs & $38.5(0.58)$ & \\
\hline 6 th, $50-59$ yrs & $37.3(0.53)$ & \\
\hline 7th, $60-69$ yrs & $37.4(0.55)$ & \\
\hline 8th, $70-79$ yrs & $34.6(0.61)$ & \\
\hline 9th, $80-89$ yrs & $35.0(0.69)$ & \\
\hline 10th, 90-99 yrs & $33.6(1.1)$ & \\
\hline
\end{tabular}

* Values are mean distance in $\mathrm{mm}$ (standard error) unless otherwise indicated.

$\dagger$ Values are mean distance in $\mathrm{mm}$ (standard deviation).

with males. Select examples are shown in Fig. 5. During the first 18 years of life, there is a significant increase in $\mathrm{McL}-\mathrm{C} 2$, which reaches a maximum in the 4th decade, accounting for a change in odontoid position relative to the hard palate of a full centimeter. Settling gradually occurs and is most notable by the age of 70 years. A mean difference of $11 \mathrm{~mm}$ was observed when comparing $\mathrm{McL}-\mathrm{C} 2$ in individuals in their 1st decade of life compared with their 4th decade, which decreased to $5 \mathrm{~mm}$ when comparing individuals in their 4th and 10th decade. A mean difference of $4 \mathrm{~mm}$ was noted when comparing males and females. The sex variation is consistent with prior stud-

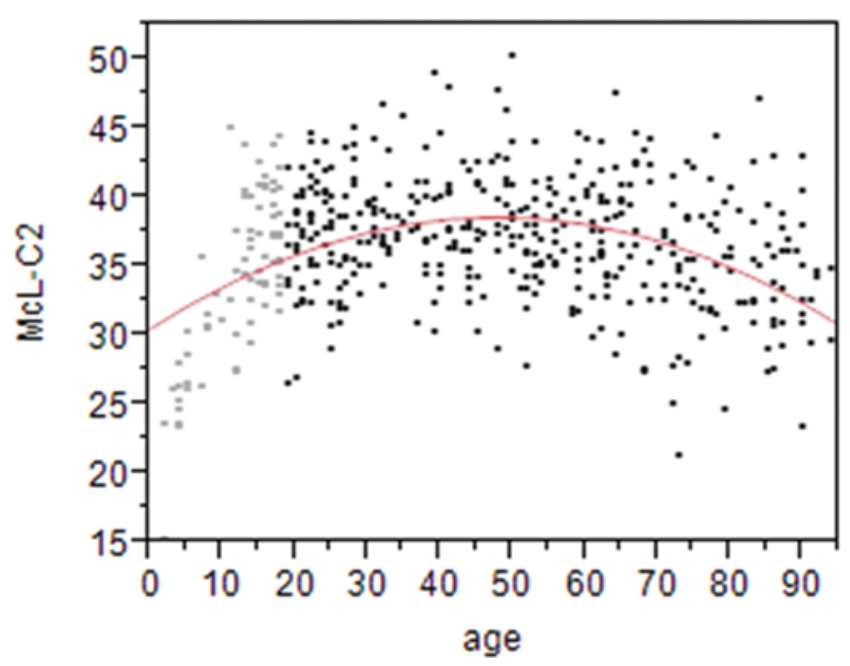

FIG. 3. Scatter plot showing the McL-C2 relative to patient age increasing up to the 4th and 5th decades followed by settling, indicating agerelated variation in the distance of $\mathrm{C}-2$ from the hard palate. Figure is available in color online only. 


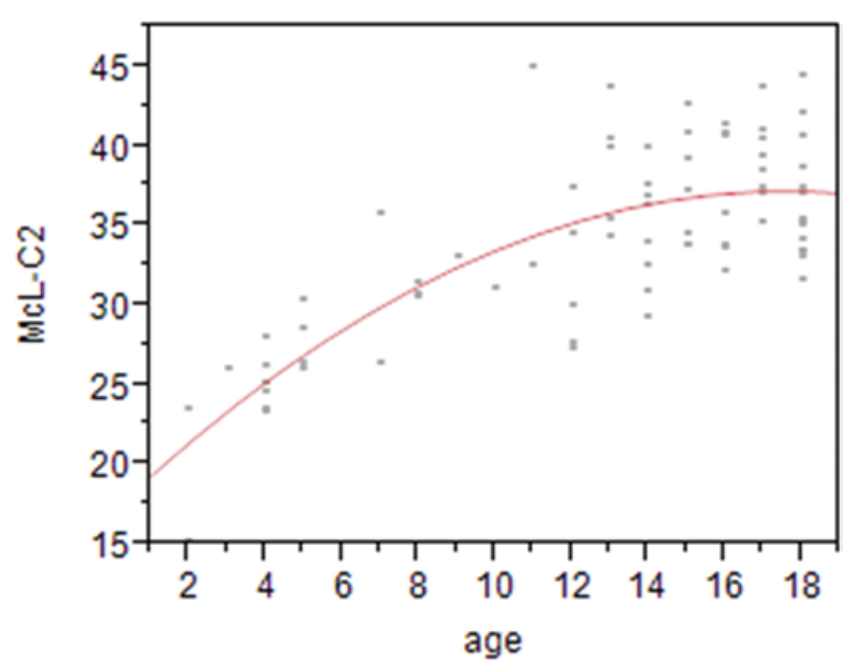

FIG. 4. Scatter plot showing an increase in McL-C2 in a pediatric cohort, indicating growth-related variation in the distances of $\mathrm{C}-2$ from the hard palate in patients under 18 years. Figure is available in color online only.

ies aiming to establish cutoffs for markers of basilar invagination. ${ }^{16,25}$ The Redlund-Johnell measurement used in this study was originally applied in the era of plain radiographs, and it was found that the cutoffs for males and females for the diagnosis of basilar invagination varied from each other by $5 \mathrm{~mm}$. More recently Kwong et al. reviewed older markers for basilar invagination such as McRae's, Wackenheim's line, McGregor's, Redlund-Johnell's line on sagittal CT scans in normal subjects to evaluate the utility of these lines in the modern era. They found a similar variation with respect to sex and, interestingly, also found that odontoid length differs according to sex (mean difference $3 \mathrm{~mm}) .{ }^{17}$ While the aforementioned studies evaluated these criteria for diagnosing basilar invagination, no prior marker was found to be over $90 \%$ sensitive, and the majority of studies were conducted using plain radiographs..$^{26,27}$ Whereas these studies looked at adults to establish cutoffs for the diagnosis, the present study specifically assessed for age-related variation on CT, not for diagnosing basilar invagination but to further elucidate the effect aging and sex have on the position of the hard palate relative to the craniocervical junction, and to establish its relevance in selecting approaches to the craniocervical junction.

The hard palate is a major bony landmark, which has recently been used to predict the extent of endoscopic surgical corridors (EN and EO) for approaching the craniocervical junction. ${ }^{1,8,18}$ The nasopalatine, a line drawn from the rhinion to the posterior nasal spine of the hard palate, was found to correlate with the inferior extent of resection achieved via an EN approach by de Almeida et al. Using preoperative CT scans obtained in patients undergoing odontoidectomy, de Almeida found that the nasopalatine line typically intersected the spine within $8.9 \mathrm{~mm}$ above the $\mathrm{C}-2$ body, defining the inferior extent of surgical dissection. ${ }^{8}$ Similarly, Lega et al. reviewed 41 CT scans obtained in normal individuals and found that the nasopalatine line intersected the C-2 body, on average, $22 \mathrm{~mm}$ below the hard palate, defining the extent of the EN approach, whereas the oropalatine line (used to define the steepest upward trajectory of an EO approach based on maximal opening of the oral cavity) typically intersected the clivus $38 \mathrm{~mm}$ above the basion. ${ }^{19}$ Aldana and colleagues further evaluated the caudal extent of the EN corridor in 9 cadavers and found that a separate nasoaxial line, the intersection of the halfway point between the rhinion and anterior nasal spine and the posterior nasal spine, better predicted the inferior extent of resection. ${ }^{1}$ Still, La Corte and colleagues again evaluated the inferior extent of resection in patients undergoing EN odontoidectomy and now describe a new rhinopalatine line (two-thirds between the anterior nasal
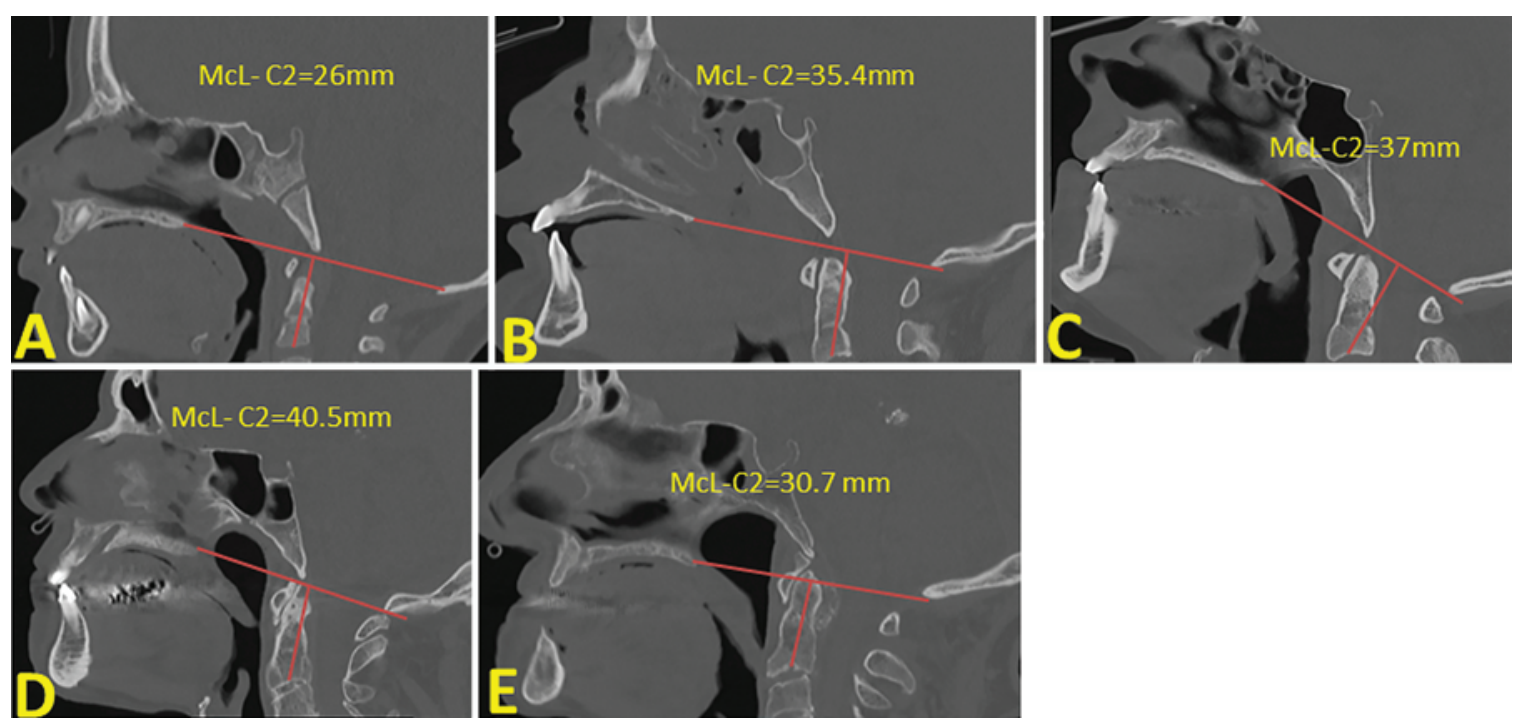

FIG. 5. Representative CT scans showing measured distances from C-2 to McGregor's palatoccipital line (McL-C2) obtained in a 3 -year-old male (A), 14-year-old male (B), 32-year-old male (C), 60-year-old male (D), and 94-year-old female (E). Figure is available in color online only. 
spine and rhinion intersecting the posterior nasal spine), which better predicts the inferior extent of EN corridor. Despite differences in methodology, the aforementioned studies do establish the hard palate's relationship to the craniocervical junction as being partially determinant of the surgical corridor obtained by either a transnasal or transoral vector. Recently, Dlouhy et al. have further modified their algorithm originally proposed at University of Iowa for addressing craniovertebral junction pathology and now include the position of the nasopharynx and oropharynx relative to the hard palate as a discriminator of the surgical approach (endonasal, transoral, or transcervical) chosen in cases with irreducible pathology. ${ }^{9}$

In contrast to studies that evaluate surgical corridors in cadavers and mostly small adult cohorts, we indirectly assessed the impact of age on these corridors. Although the present study is an anatomical study based on advanced imaging, the variance with age and sex does suggest that the extent of the endoscopic corridors will also likely vary with these variables. Banu et al. recently conducted a large retrospective series involving 107 pediatric patients and found that the nare-vomer distance varied significantly with respect to age, and the nare-sellar distance differed significantly with sex. ${ }^{4}$ No differences, however, were noted in nasal restriction sites with respect to age, such as the width between middle turbinates or nasal aperture, suggesting access can be gained to pathology of the anterior craniocervical junction despite age and sex variance provided working angles and distances are favorable. Based on the results of this study, we surmise that the inferior extent of the EN approach is likely increased in individuals at the extremes of age (pediatrics and the elderly) relative to middle-aged individuals and similarly in females compared with males. Conversely, the EO or standard transoral approach may have increased superior extent and improved access to $\mathrm{C}-2$ in middle-aged individuals. These findings, however, need further validation as the surgical environment and positioning may further change surgical access. ${ }^{18,20}$

Although this work characterizes the variation of distances between C-2 and the hard palate, which is an important variable for deciding between operative approaches, this study does have several limitations. Foremost, pathology often alters anatomy, thus the anatomical information gleaned from this study may not be generalized to cases where the normal anatomy has been distorted..$^{11,28}$ Secondly, the nasal and oral cavities were not visualized in their entirety in all of the radiographic studies examined, which would have been helpful for further assessing the steepest angles afforded by EO and EN approaches, and for direct comparison with studies that used different reference lines for determining sagittal extent. The relationship of C-2 and the hard palate was examined only in the sagittal plane on CT scans. Further study using other imaging modalities (e.g., MRI) as well as correlation with intraoperative and postoperative imaging will be necessary to evaluate the impact that age-sex variance has on surgical corridors. Next, pediatric patients are relatively underrepresented; thus the increment of change in the selected parameter, which likely occurs with growth, is not fully appreciated. Lastly, while the present study does suggest that the surgical corridors likely vary according to age, it is important to acknowledge that individual patient anatomy, pathology, and surgeon experience will ultimately dictate the approach selected. Although the present study has implications that mostly apply to endoscopic corridors, the traditional transoral route under the operative microscope does allow for treatment of the variety of pathology involving the craniocervical junction. ${ }^{23}$ Endoscopic approaches at this juncture are relatively newer and may be useful in mitigating the morbidity associated with extended transoral approaches that require splitting of the soft palate, mandibulotomy, maxillotomy, or glossotomy to increase surgical exposure., 3,5 The relatively small series examining outcomes also suggest that they may allow for earlier extubation and resumption of feeding $^{10,13,32}$ and improve visualization in a narrow corridor before performing additional tissue destruction (i.e., splitting the soft palate) ${ }^{7,16,25}$

\section{Conclusions}

The relationship of C-2 and the hard palate varies significantly with age and sex, accounting for a full centimeter in positional change through a lifetime. These findings may have particular relevance when deciding between different surgical approaches to the anterior craniocervical junction.

\section{Acknowledgments}

We would like to thank Steve Thalacker for helping to generate the records obtained for this study and for his dedicated years of service to our department and institution.

\section{References}

1. Aldana PR, Naseri I, La Corte E: The naso-axial line: a new method of accurately predicting the inferior limit of the endoscopic endonasal approach to the craniovertebral junction. Neurosurgery 71 (2 Suppl Operative):ons308-ons314, 2012

2. Baird CJ, Conway JE, Sciubba DM, Prevedello DM, Quiñones-Hinojosa A, Kassam AB: Radiographic and anatomic basis of endoscopic anterior craniocervical decompression: a comparison of endonasal, transoral, and transcervical approaches. Neurosurgery 65 (6 Suppl): 158-163, 63-64, 2009

3. Balasingam V, Anderson GJ, Gross ND, Cheng CM, Noguchi A, Dogan A, et al: Anatomical analysis of transoral surgical approaches to the clivus. J Neurosurg 105:301-308, 2006

4. Banu MA, Guerrero-Maldonado A, McCrea HJ, GarciaNavarro V, Souweidane MM, Anand VK, et al: Impact of skull base development on endonasal endoscopic surgical corridors. J Neurosurg Pediatr 13:155-169, 2014

5. Blazier CJ, Hadley MN, Spetzler RF: The transoral surgical approach to craniovertebral pathology. J Neurosci Nurs 18:57-62, 1986

6. Choi D, Crockard HA: Evolution of transoral surgery: three decades of change in patients, pathologies, and indications. Neurosurgery 73:296-304, 2013

7. Dasenbrock HH, Clarke MJ, Bydon A, Sciubba DM, Witham TF, Gokaslan ZL, et al: Endoscopic image-guided transcervical odontoidectomy: outcomes of 15 patients with basilar invagination. Neurosurgery 70:351-360, 2012

8. de Almeida JR, Zanation AM, Snyderman CH, Carrau RL, Prevedello DM, Gardner PA, et al: Defining the nasopalatine line: the limit for endonasal surgery of the spine. Laryngoscope 119:239-244, 2009 
9. Dlouhy BJ, Dahdaleh NS, Menezes AH: Evolution of transoral approaches, endoscopic endonasal approaches, and reduction strategies for treatment of craniovertebral junction pathology: a treatment algorithm update. Neurosurg Focus 38(4):E8, 2015

10. Duntze J, Eap C, Kleiber JC, Théret E, Dufour H, Fuentes S, et al: Advantages and limitations of endoscopic endonasal odontoidectomy. A series of nine cases. Orthop Traumatol Surg Res 100:775-778, 2014

11. El-Sayed IH, Wu JC, Dhillon N, Ames CP, Mummaneni P: The importance of platybasia and the palatine line in patient selection for endonasal surgery of the craniocervical junction: a radiographic study of 12 patients. World Neurosurg 76:183-188, 74-78, 2011

12. Frempong-Boadu AK, Faunce WA, Fessler RG: Endoscopically assisted transoral-transpharyngeal approach to the craniovertebral junction. Neurosurgery 51 (5 Suppl):S60-S66, 2002

13. Goldschlager T, Härtl R, Greenfield JP, Anand VK, Schwartz TH: The endoscopic endonasal approach to the odontoid and its impact on early extubation and feeding. J Neurosurg 122:511-518, 2015

14. Guan MW, Wang JY, Feng DX, Fu P, Chen LH, Li MC, et al: Anatomical study of endoscope-assisted far lateral keyhole approach to the ventral craniocervical region with neuronavigational guidance. Chin Med J (Engl) 126:1707-1713, 2013

15. Kassam AB, Snyderman C, Gardner P, Carrau R, Spiro R: The expanded endonasal approach: a fully endoscopic transnasal approach and resection of the odontoid process: technical case report. Neurosurgery 57 (1 Suppl):E213, 2005

16. Komotar RJ, Starke RM, Raper DM, Anand VK, Schwartz TH: The endoscope-assisted ventral approach compared with open microscope-assisted surgery for clival chordomas. World Neurosurg 76:318-327, 259-262, 2011

17. Kwong Y, Rao N, Latief K: Craniometric measurements in the assessment of craniovertebral settling: are they still relevant in the age of cross-sectional imaging? AJR Am J Roentgenol 196:W421-W425, 2011

18. La Corte E, Aldana PR, Ferroli P, Greenfield JP, Härtl R, Anand VK, et al: The rhinopalatine line as a reliable predictor of the inferior extent of endonasal odontoidectomies. Neurosurg Focus 38(4):E16, 2015

19. Lega BC, Kramer DR, Newman JG, Lee JY: Morphometric measurements of the anterior skull base for endoscopic transoral and transnasal approaches. Skull Base 21:65-70, 2011

20. Lin ZK, Chi YL, Wang XY, Yu Q, Fang BD, Wu LJ: The influence of cervical spine position on the three anterior endoscopic approaches to the craniovertebral junction: an imaging study. Spine J 14:80-86, 2014

21. Liu JK, Couldwell WT, Apfelbaum RI: Transoral approach and extended modifications for lesions of the ventral foramen magnum and craniovertebral junction. Skull Base 18:151166,2008

22. McGregor M: The significance of certain measurements of the skull in the diagnosis of basilar impression. Br J Radiol 21:171-181, 1948

23. Menezes AH, VanGilder JC: Transoral-transpharyngeal approach to the anterior craniocervical junction. Ten-year experience with 72 patients. J Neurosurg 69:895-903, 1988
24. Messina A, Bruno MC, Decq P, Coste A, Cavallo LM, de Divittis E, et al: Pure endoscopic endonasal odontoidectomy: anatomical study. Neurosurg Rev 30:189-194, 2007

25. Pillai P, Baig MN, Karas CS, Ammirati M: Endoscopic image-guided transoral approach to the craniovertebral junction: an anatomic study comparing surgical exposure and surgical freedom obtained with the endoscope and the operating microscope. Neurosurgery 64 (5 Suppl 2):437-444, 2009

26. Redlund-Johnell I, Pettersson H: Radiographic measurements of the cranio-vertebral region. Designed for evaluation of abnormalities in rheumatoid arthritis. Acta Radiol Diagn (Stockh) 25:23-28, 1984

27. Riew KD, Hilibrand AS, Palumbo MA, Sethi N, Bohlman $\mathrm{HH}$ : Diagnosing basilar invagination in the rheumatoid patient. The reliability of radiographic criteria. J Bone Joint Surg Am 83-A:194-200, 2001

28. Singh H, Harrop J, Schiffmacher P, Rosen M, Evans J: Ventral surgical approaches to craniovertebral junction chordomas. Neurosurgery 66 (3 Suppl):96-103, 2010

29. Spetzler RF, Hadley MN, Sonntag VK: The transoral approach to the anterior superior cervical spine. A review of 29 cases. Acta Neurochir Suppl (Wien) 43:69-74, 1988

30. Van Abel KM, Mallory GW, Kasperbauer JL, Moore EJ, Price DL, O'Brien EK, et al: Transnasal odontoid resection: is there an anatomic explanation for differing swallowing outcomes? Neurosurg Focus 37(4):E16, 2014

31. Wang Y, Yang M, Zhang H, Zheng Y, Tian Y, Li Y: Exploring the safety range via the transoral approach to the craniovertebral junction. J Craniofac Surg 25:1473-1475, 2014

32. Wolinsky JP, Sciubba DM, Suk I, Gokaslan ZL: Endoscopic image-guided odontoidectomy for decompression of basilar invagination via a standard anterior cervical approach. Technical note. J Neurosurg Spine 6:184-191, 2007

\section{Disclosures}

Dr. Fogelson reports being a consultant with DePuy Synthes.

\section{Author Contributions}

Conception and design: Van Gompel, Mallory, Wetjen, Fogelson, Clarke, Eckel. Acquisition of data: Mallory, Arutyunyan, Murphy, Francois. Analysis and interpretation of data: Van Gompel, Mallory, Arutyunyan, Murphy, Francois, Clarke. Drafting the article: Van Gompel, Mallory, Murphy, Van Abel, Wetjen, Fogelson, O'Brien. Critically revising the article: Van Gompel, Mallory, Arutyunyan, Murphy, Van Abel, Wetjen, Fogelson, O'Brien, Clarke, Eckel. Reviewed submitted version of manuscript: Van Gompel, Mallory, Arutyunyan, Van Abel, Francois, Wetjen, Fogelson, O'Brien, Clarke, Eckel. Approved the final version of the manuscript on behalf of all authors: Van Gompel. Statistical analysis: Van Gompel, Mallory. Administrative/technical/material support: Van Abel, Eckel.

\section{Correspondence}

Jamie J. Van Gompel, Department of Neurosurgery, Mayo Clinic, 200 First St. SW, Rochester, MN 55905. email: vangompel. jamie@mayo.edu. 